\title{
Atividade das glicosidases na presença de chá verde e de chá preto
}

PEREIRA, L.L.S. *; SOUZA, S.P.; SILVA, M.C; CARVALHO, G.A.; SANTOS, C.D.; CORRÊA, A.D.; ABREU, C.M.P. Departamento de Química / Universidade Federal de Lavras (UFLA), Caixa Postal 3037, CEP:37200-000, LavrasBrasil*lucianalsp@yahoo.com.br

\begin{abstract}
RESUMO: Várias plantas têm sido consideradas produtos terapêuticos, dentre elas destacamse os chás verde e preto, popularmente utilizados para controle da hiperglicemia e obesidade. Objetivou-se neste trabalho avaliar o potencial inibitório sobre as enzimas $\alpha$-amilase, $\alpha$ e $\beta$ glicosidases e o teor de compostos fenólicos do chá verde e do chá preto. O teor de compostos fenólicos encontrados foram de $80,8 \pm 0,43 \mathrm{mg} \mathrm{g}^{-1}$ no chá preto e $32,0 \pm 0,12 \mathrm{mg} \mathrm{g}^{-1}$ no chá verde. O chá verde e o chá preto, em condições de consumo, inibiram as enzimas em estudo, porém, após a simulação do fluido gástrico o inibidor presente no chá verde perdeu a ação. O chá preto deixou de inibir a $\alpha$-amilase e apresentou inibição inalterada para $\alpha$ e $\beta$-glicosidases. Tais resultados sugerem que o chá preto pode ser auxiliar em dietas de restrição de carboidratos.
\end{abstract}

Palavras-chave: Camellia sinensis, inibição enzimática, hiperglicemia, obesidade

\begin{abstract}
Activity of glycosidases in the presence of green tea and black tea. Several plants have been considered therapeutic products, including green and black tea, popularly used to control hyperglycemia and obesity. This study aimed to evaluate the inhibitory potential of the enzymes $\alpha$-amylase, $\alpha$ and $\beta$-glycosidases, as well as the content of phenolic compounds in green tea and black tea. The concentrations of phenolic compounds found were $80.8 \pm 0.43 \mathrm{mg} \mathrm{g}^{-1}$ in black tea and $32.0 \pm 0.12 \mathrm{mg} \mathrm{g}^{-1}$ in green tea. Under the tested conditions of use, green and black tea inhibited the enzyme under study. However, after simulation of the gastric fluid, the inhibitor present in green tea lost its action. Black tea no longer inhibited a-amylase and showed unaltered inhibition for $\alpha$ and $\beta$-glycosidases. These results suggest that black tea can be helpful in diets restricting carbohydrates.
\end{abstract}

Key words: Camellia sinensis, enzymatic inhibition, hyperglycemia, obesity

\section{INTRODUÇÃO}

Desde a pré-história, as plantas têm sido utilizadas como produtos terapêuticos. Em todo mundo milhares de produtos de origem vegetal são utilizados nas mais variadas formas como cataplasmas, infusão, macerado, filtrado, tinturas, pomadas, xarope, cápsulas e na forma in natura. $\mathrm{O}$ chá é uma das bebidas mais consumidas e mais antigas do mundo.

O chá verde e o chá preto são preparados com folhas da mesma planta [Camellia sinensis (L.) O. Kuntze], pertencente à família Theaceae. O chá verde é constituído de folhas secas colhidas de diferentes partes da planta. Já o chá preto passa por diversas etapas de processamento, dentre elas a de "fermentação", que consiste, na verdade, de oxidação enzimática dos flavanóis a teaflavinas, que constituem um grupo característico deste tipo de chá (Matsubara \& Amaya, 2006).

Um dos principais componentes químicos presentes nos chás, os compostos fenólicos cuja característica estrutural comum que é a presença de um anel aromático hidroxilado, interage com as proteínas formando complexos, possivelmente inibindo algumas enzimas (Salunkhe et al., 1990). O uso de fármacos derivados de plantas medicinais movimenta um mercado importante, especialmente na Europa, Países Asiáticos e Estados Unidos. Este mercado se baseia em pesquisa básica e clínica, porém o uso cotidiano sem respaldo científico é ainda maior (Lima et al., 2008).

Assim o uso empírico do chá verde e do chá preto com finalidades emagrecedora e hipoglicemiante

Recebido para publicação em 29/04/2009

Aceito para publicação em 11/04/2010

Rev. Bras. PI. Med., Botucatu, v.12, n.4, p.516-518, 2010. 
pode estar relacionado à inibição das enzimas digestivas que hidrolisam os carboidratos. Dentre essas enzimas estão as $\alpha$-amilases que catalisam a hidrólise da ligação glicosídica $\alpha-1,4$ do amido, glicogênio, e vários oligossacarídeos para posterior ação das glicosidases, liberando açúcares simples para serem absorvidos nas membranas dos enterócitos. A inibição da atividade destas enzimas no trato digestivo de humanos é relevante no controle da obesidade ou diabetes, por diminuir a absorção de glicose (Negri, 2005). Objetivou-se neste trabalho avaliar o teor de compostos fenólicos do chá verde e do chá preto e o potencial inibitório sobre as enzimas digestivas $\alpha$-amilase, $\alpha$ e $\beta$-glicosidases.

\section{MATERIAL E MÉTODO}

\section{Preparo das enzimas}

A enzima $\alpha$-amilase pancreática suína foi do tipo VI da SIGMA. As $\alpha$ e $\beta$-glicosidases foram obtidas a partir de duodeno suíno, cedido pelo Departamento de Zootecnia da UFLA. O tecido foi triturado em liquidificador para extração da enzima das membranas dos enterócitos e processado em mixer até completa homogeneização. O homogeneizado foi filtrado em malha de nylon e centrifugado por 10 minutos a $3000 \mathrm{rpm}$. O sobrenadante foi recolhido e utilizado como extrato enzimático.

\section{Preparo dos chás}

O chá verde tostado e o chá preto (Camellia sinensis) foram adquiridos em supermercado local, na forma de sachet. Foram pesados 2 gramas dos chás e colocados em infusão com $50 \mathrm{~mL}$ de água fervente por 10 minutos. Após esfriar, foram filtrados em papel de filtro e utilizados como inibidores nas análises enzimáticas.

\section{Simulação da digestão no estômago}

Os chás foram incubados com o fluido gástrico simulado preparado segundo a USP (1995), por 1 hora em banho-maria a $37^{\circ} \mathrm{C}$. Após esse período, foram neutralizados com bicarbonato de sódio puro até $\mathrm{pH}$ fisiológico.

\section{Ensaio da atividade das enzimas glicolíticas}

A determinação da atividade de $\alpha$-amilase foi feita segundo Noelting \& Bernfeld (1948), utilizando amido $1 \%$ em tampão Tris $0,05 \mathrm{M} \mathrm{pH} \mathrm{7,0} \mathrm{como}$ substrato. As atividades de $\alpha$-glicosidase e $\beta$ glicosidade foram determinadas segundo o método proposto por Kwon et al. (2006) com modificações. $O$ substrato constituído de $p$-nitrofenil- $\alpha$-Dglicopiranosideo $0,005 \mathrm{~mol} \mathrm{~L}^{-1}$ e $p$-nitrofenil- $\beta$-Dglicopiranosideo, foram preparados em tampão citratofosfato $0,1 \mathrm{~mol} \mathrm{~L}^{-1} \mathrm{pH} 7,0$.
Todas as análises foram feitas em triplicata. Em cada análise a mistura de reação foi incubada por pelo menos quatro períodos de tempo. Controles sem enzima (branco de substrato) (a) e sem substrato (branco enzima) foram incubados em banho-maria a $37^{\circ} \mathrm{C}$ por 10, 20, 30 e 40 minutos, do mesmo modo que os experimentais. A inclinação da reta (gráfico absorbância $X$ tempo), diretamente proporcional à atividade enzimática, foi calculada e utilizada para os cálculos de porcentagem de inibição. Os comprimentos de onda foram $540 \mathrm{~nm}$ para $\alpha$-amilase e $410 \mathrm{~nm}$ para a $\alpha$ e $\beta$-glicosidases.

\section{glicolíticas}

\section{Ensaio da inibição das enzimas}

A inibição das enzimas $\alpha$-amilase, $\alpha$ e $\beta$ glicosidases foi obtida a partir dos ensaios na ausência do inibidor (A), na ausência do inibidor e da enzima (a), na presença do inibidor, enzima e substrato (B) e na ausência da enzima (b) da mesma forma que o ensaio de atividade das enzimas. Em cada análise de inibição os chás foram pré-incubados com a enzima por 20 minutos antes da adição do substrato e início da contagem do tempo. A porcentagem de inibição (I) foi calculada pela equação:

$$
I \%=\frac{(A-a)-(B-b)}{(A-a)} \times 100
$$

\section{Determinação de polifenóis}

Em 1 grama de chá foram adicionados $50 \mathrm{~mL}$ de metanol $50 \%$ em e aquecidos em refluxo a $80^{\circ} \mathrm{C}$ durante 15 minutos. $O$ extrato foi filtrado em papel e a fração recolhida. O filtro de papel foi lavado com 50 $\mathrm{mL}$ de metanol $50 \%$ e procedeu-se à extração dos polifenóis como descrito anteriormente. Esse processo foi repetido mais uma vez e as três frações foram reunidas, evaporadas até o volume de $25 \mathrm{~mL}$ e submetidas à dosagem de polifenóis, usando ácido tânico como padrão (Golsdtein \& Swain, 1963).

\section{RESULTADO E DISCUSSÃO}

A inibição das enzimas envolvidas na digestão de carboidratos foi verificada in vitro sem simulação e com o fluido gástrico e com simulação do fluido e está demonstrada na Tabela 1.

$\mathrm{Na}$ avaliação da atividade glicolítica da $\alpha$ amilase, $\alpha$ e $\beta$-glicosidases na presença dos chás verde e preto, foi verificada inibição destas. O chá preto apresentou inibição superior ao chá verde sobre estas três enzimas, sendo a $\alpha$-amilase a mais inibida. Kwon et al. (2006), avaliando a inibição de vinhos e chás sobre a $\alpha$-glicosidase e $\alpha$-amilase, também encontraram maior inibição pelo chá preto. Essa inibição tem sido relacionada com a presença de compostos fenólicos nos chás, devido à característica 
TABELA 1. Percentual de inibição de $\alpha$-amilase, $\alpha$ e $\beta$-glicosidase pelo chá verde e chá preto.

\begin{tabular}{|c|c|c|c|c|}
\hline \multirow[t]{2}{*}{ Enzimas } & \multicolumn{2}{|c|}{ Chá verde } & \multicolumn{2}{|c|}{ Chá preto } \\
\hline & \% Inibição & \% Inibição & \% Inibição & \% Inibição \\
\hline$\alpha$-amilase & 42,19 & 0 & 73,44 & 0 \\
\hline$\alpha$-glicosidase & 37,00 & 0 & 48,00 & 48,00 \\
\hline B-glicosidase & 17,00 & 0 & 37,00 & 37,00 \\
\hline
\end{tabular}

"Sem simulação da digestão " Com simulação da digestão

estrutural comum a todos eles que é a presença de um anel aromático hidroxilado, que interage com as proteínas causando complexação (Salunkhe et al., 1990).

O teor de compostos fenólicos encontrados foram de $80,8 \pm 0,43 \mathrm{mg} \mathrm{g}^{-1}$ no chá preto e $32,0 \pm$ $0,12 \mathrm{mg} \mathrm{g}^{-1}$ no chá verde. O elevado teor de polifenóis encontrado no chá preto $\left(80,8 \mathrm{mg} \mathrm{g}^{-1}\right)$ pode estar associado a maior inibição das enzimas. Prado et al. (2005), quantificando polifenóis em Camelia sinensis, encontraram para chá verde níveis entre 3,4 e 6,2\% valores semelhantes aos obtidos neste trabalho $(3,2 \%)$.

Na ingestão do chá, a passagem pelo trato gastrintestinal pode acarretar modificações estruturais no inibidor em decorrência do pH ácido do estômago, inativando-o.

Alguns autores citam o uso do chá verde e chá preto como adjuvantes ao tratamento da hiperglicemia pela inibição da $\alpha$-amilase (Hara \& Honda, 1990; Know et al., 2006; Kusano et al., 2008). No entanto, a simulação gástrica sugere que não há inibição in vivo.

O inibidor das glicosidases presente no chá preto não perdeu a atividade após incubação com fluido gástrico simulado, mostrando-se uma alternativa em potencial para o tratamento de diabetes tipo II e obesidade, por diminuir a absorção de carboidratos.

\section{CONCLUSÃO}

O chá verde e o chá preto em condições de consumo inibem as enzimas envolvidas na digestão de carboidratos. Porém após a simulação do fluido gástrico o inibidor presente no chá verde perde a ação. O chá preto deixa de inibir a a-amilase e apresenta inibição inalterada nas a e b-glicosidases.

\section{REFERÊNCIA}

GOLDSTEIN, J.L.; SWAIN, T. Changes in tannins in ripening fruits. Phytochemistry, v.2, p.371-83, 1963.

HARA, Y.; HONDA, M. The inhibition of $\alpha$-amylase by tea polyphenols. Agricultural and Biological_Chemistry, v.54, n.8, p.1939-45, 1990.

KUSANO, R. et al. Polymer-like polyphenols of black tea and their lipase and amylase inhibitory activities. Chemical \& Pharmaceutical Bulletin, v.56, n.3, p.26672, 2008.

KWON, Y.I.; APOSTOLIDIS, E.; SHETTY, K. Inhibitory potential of wine and tea against $\alpha$-glucosidase for management of hyperglycemia linked to type 2 diabetes. Journal of Food Biochemistry, v.32, p.15-31, 2006.

LIMA, S.T. Levantamento da flora medicinal usada no tratamento de doenças metabólicas em Salvador, BABrasil. Revista Brasileira de Plantas Medicinais, v.10, n.4, p.83-9, 2008.

MATSUBARA, S.; AMAYA, D.B.R. Conteúdo de miricetina, quercetina e kaempferol em chás comercializados no Brasil. Ciência e Tecnologia de Alimentos, v.26, n.2, p.380-5, 2006.

NEGRI, G. Diabetes melito: plantas e princípios ativos naturais hipoglicemiantes. Revista Brasileira de Ciências Farmacêuticas, v.41, p.121-42, 2005.

NOELTING, G.; BERNFELD, P. Sur les enzymes amylolytiques III. La amylase: dosage d'activate et controle de l' $\alpha$-amilase. Helvetica Chimica Acta, v.31, n.1, p.286-90, 1948.

PRADO, C.C. et al. Avaliação do teor de polifenóis da Camellia sinensis (chá verde). Revista Eletrônica de Farmácia, v.2, n.2, p.164-7, 2005.

SALUNKHE, D.K.; CHAVAN, J.K.; KADAM, S.S. Dietary tannins: consequences and remedies. Boca Raton: CRC Press, 1990. 200p.

USP XXIII - The United States Pharmacopeia - The National Formulary NF 18. Rockvile, MD: United States Pharmacopeial Convention Inc, 1995. 